\title{
Xenoestrogens in Sealants and Composites
}

\author{
Aditi Bector*, Sumeet Rajpal and Mrigank Dogra \\ Department of Pediatric and preventive dentistry, Rayat Bahra dental college and hospital, India
}

Received: March 20, 2018; Published: April 09, 2018

*Corresponding author: Aditi Bector, Department of Pediatric and preventive dentistry, Rayat Bahra dental college and hospital, Mohali, India, Tel: 91 9815010137; Email: draditibector@gmail.com

\begin{abstract}
Estrogenicity of Bisphenol A (BPA) based dental sealants and composites used in dentistry have been reported in literature. Leaching of these monomers from resins can occur during the initial setting period and in conjunction with fluid sorption and desorption over time. This review presents various studies which evaluated the presence/absence of BPA in oral cavity after application of dental materials. We further recommend minimized use of these materials during pregnancy, treatment of surface layer if applied and encourage the use of BPA free sealants.
\end{abstract}

\section{Introduction}

Compounds that represent estrogen in their effects but not necessarily in chemical structure are known as Xenoestrogens [1]. Bisphenol A is one such kind with ubiquitous human exposure. It was synthesized 100 years ago and was briefly used in the 1930's as a substitute for estrogen until replaced with diethyl-stilbestrol (DES) $[2,3]$. It exists at room temperature as a white solid with a mild odour similar to phenol [4] and is a synthetic chemical resin used in production of plastic products [5]. Derivatives of BPA are components of resin-based sealants and composites used in preventive and restorative dentistry. These are liquid monomers that polymerize into a solid on chemical or light curing. Incomplete polymerisation leads to leaching of BPA from sealants, which is thereby released into the oral cavity and systemically absorbed by the patient [6]. As saliva inhibits the polymerization of pure BPA by causing hydrolysis of the second end hydroxyl groups $[7,8]$ BPA glycidyl dimethacrylate (bis-GMA or bowens resin), is most frequently used as the base of the resin. Other BPA derivatives used in resins include:
a. BPA dimethacrylate (bis-DMA)
b. BPA diglycidylether (BADGE)
c. BPA ethoxylate dimethacrylate (bis-EMA)
d. Urethane-modified bis-GMA.

To maximise the viscosity of the resin, TEGDMA (Triethylene glycol dimethacrylate) and UDMA (urethane dimethacrylate) are added [7]. Incomplete chemical curing of composites result in some residual monomers remaining intact and leaching out of the cured resin into the surrounding media [9]. Bis-DMA undergoes hydrolysis by salivary enzyme esterases, releasing pure BPA, whereas Bis-GMA does not undergo this reaction, as its chemical structure prevents hydrolysis at the ester linkage $[10,11]$. Researchers have found an estrogenic effect with BPA, Bis-DMA, and Bis-GMA but not with TEGDMA, in an estrogen-sensitive cell line-MCF7 [12].

\section{Estrogenicity}

Compared to estradiol, Bisphenol-A binds weakly to nuclear estrogen receptors, [13] but shows more potent activity at nonclassical membrane receptors [14]. Various in vivo studies in rats have shown an increase in uterine weight, premature vaginal opening, [15] and increased differentiation and proliferation of mammary epithelial cells in females on exposure to BPA [16]. Some in vitro studies have found BPA and bis- DMA to be estrogenic but not bis-GMA $[8,17,18]$. BPA and bis-DMA were shown to be agonists to estrogen, antagonists to androgen, and inhibitors of aromatase activity at the receptor level. Mariotti et al. [19,20] has revealed an increased uterine wet weight and uterine collagen content in ovariectomized mice due to high doses of Bis-GMA [20].

\section{Human Health Risks of BPA}

BPA disrupts secretion of gonadotrophic hormones in men, and has been associated with recurrent miscarriages in females [2123]. The FDA has strictly discouraged the use of BPA-based epoxy resins as coatings in packaging for infant formula [24]. However, it has been reported that BPA in the 'low dose' region from 2.5 to $2,700 \mu \mathrm{g} / \mathrm{kg} \mathrm{bw} /$ day did not produce adverse effects [25].

\section{Evidence For Cytotoxicity of Sealants And Composites}

Olea et al. [26] studied the possible estrogenic activity of both bis-GMA resin-based composites and sealants. 3 different brands of composite resin and 2 batches of a single brand of a dental 
sealant material were included in the study. Samples of saliva from 18 subjects treated with $50 \mathrm{mg}$ of a bis-GMA-based sealant applied on their molars were collected $1 \mathrm{hr}$ before and after treatment. BPA (range 90-931 micrograms) was identified only in saliva collected during a 1-hr period after treatment. The authors concluded that the use of bis-GMA-based resins in dentistry, contributed to human exposure to xenoestrogens. Quinlan et al. [27] investigated the potential cytotoxicity of two of the newer dental restorative materials, Spectrum composite resin and Dyract AP compomer. Assessment of cellular viability indicated that both materials cause cell death, with Spectrum being the more toxic.

An association was observed between inadequate light cure and toxicity of restorative materials. Cytotoxic effects and the formation of micronuclei were determined in V79 fibroblasts after exposure to extracts of modern composite filling materials (Solitaire, Solitaire 2, Tetric Ceram, Dyract AP, and Definite). The ranking of the cytotoxic effects of the composites according to EC50 values after a 24-h exposure period was as follows: Solitaire (most toxic) $=$ Solitaire $2<$ Tetric Ceram $<$ Dyract $\mathrm{AP}<$ Definite (least toxic). The authors suggested that mutagenic components of biologically active composite resins should be replaced with more biocompatible substances to avoid health risks for patients and dental personnel. Pulgar et al. [28,29] studied biphenolic components eluted from seven composites and one sealant before and after in vitro polymerization using HPLC and gas chromatography/mass spectrometry and investigated how $\mathrm{pH}$ modifications affect the leaching of these components.

Leaching of estrogenic monomers into the environment by Bis-GMA-based composites and sealants in concentrations that were estrogenic was confirmed. Nocca et al. [30] evaluated in vitro cytopathic effects of a self-curing and a light-curing orthodontic composite resin by a cytotoxicity test and reported that the examined chemical-cured material is more cytotoxic than the lightcured one. In a study carried out by Tell et al. [31], the potential toxic effects of several orthodontic adhesives (Monolok, Unite, One to One, Adaptic, Orthomite) immediately after polymerization and at various time intervals up to 2 years after polymerization were evaluated. All materials tested showed cytotoxic effects immediately after polymerization and the toxic effect decreased with time and after polymerization. However, even 2 years after the initial polymerization, toxicity was still evident in all adhesives except Orthomite. Al-Hiyasat et al. [32] investigated the cytotoxicity of 3 types of dental composites.

Fifteen specimens of the composites and 15 specimens of their flowable derivatives were used to determine the compounds released from these materials. Flowable derivatives were found to be more cytotoxic than traditional composites. In an in vitro study, the estrogenic activity of eluates obtained from 24 resin composites placed into a steel mould, and 18 chemicals with concentration equal to $100 \mathrm{nmol} / \mathrm{L}$ identified from the composites tested, were examined with the use of the reporter gene assay .They revealed estrogenic activity in vitro for six of the 24 composites, and three of the 18 constituents: a photo stabilizer (HMBP), a photo initiator (DMPA) and an inhibitor (BHT) [33].

\section{Evidence Against Cytotoxicity of Sealants and Compos- ites}

Fung et al. [34] conducted a study to determine the rate and time course of BPA released from a dental sealant (Delton LC) when applied at a single $8-\mathrm{mg}$ dose (1 tooth) or $32 \mathrm{mg}$ (8 $\mathrm{mg}$ on each of 4 teeth) to the teeth of 40 healthy adults with no sealant or restorative history . The authors collected saliva (30 milliliters) and blood $(7 \mathrm{~mL})$ specimens from all subjects immediately before sealant placement (baseline) and at one hour, three hours, one day, three days and five days after sealant placement. BPA was detectable in some saliva specimens collected at 1 hour and 3 hours; and not detectable in the saliva samples beyond 3 hours or in any of the serum specimens. The authors concluded that BPA released orally from a sealant may be present in nondetectable amounts in systemic circulation. Ortengren [35] assessed the water sorption and solubility of 6 proprietary composite resin materials and found no detectable quantities of BPA during the test period.

Nomura et al. [36] tested 3 monomers (bis-GMA, urethane dimethacrylate and TEGDMA) and 5 polymerization initiators (camphorquinone, benzoyl peroxide, dimethyl para toluidine, 2-dimethylamino-ethylmethacrylate and 1-allyl-2-thiourea) commonly used in dental composite resins for estrogenic activity and compared these with BPA. The authors found no estrogenic agonist activity for any of these 8 monomer and polymerization initiators. Zimmerman-Downs et al. [37] examined the effects of a widely used pit and fissure sealant material on BPA levels in blood and saliva, among both low and high-dose groups over time. Salivary BPA concentration levels peaked over a 3 hour period following sealant placement and returned to baseline levels within 24 hours.

The blood serum did not contain BPA at any point. Authors concluded that BPA is not absorbed into the blood circulatory system after exposure has occurred from the dental sealant. Kostoryz et al. [38], in an vitro study observed that Bisphenol A bis (2,3-dihydroxypropyl) ether and bisphenol $F$ bis (2,3-dihydroxypropyl) ether were non-mutagenic, non-estrogenic, and presented minor cytotoxicity. Manabe et al. [39], using in vitro an original method of selective extraction in combination with gas chromatography-mass spectrometry, revealed that BPA can be released from dental materials, however the leachable amount would be less than $1 / 1000$ of the reported dose $(2 \mathrm{~g} / \mathrm{kg}$ body weight/day) required for xenoestrogenicity in vivo. An in vitro study was carried out by Hamid and Hume, [40] to identify and quantify the major components released from any of seven commerciallyavailable, light-cured pit and fissure sealants using HPLC. TEGDMA was present in all eluates from each of the sealants tested whereas BisGMA was detected at much lower levels (about one thousandfold less) in eluates from one sealant only. Bisphenol-A was not detected in any eluates. 
In an in vitro study Lewis et al. [41] identified the release of BPA and BPA dimethacrylate from 28 commercial dental products using HPLC, and found no measurable released quantities of these compounds, except one. The authors concluded that dental resins in general do not represent a significant source of BPA. Schmalz et al. [42] chemically analyzed the BPA content of different fissure sealant resin monomers and their release of BPA under hydrolytic conditions, by HPLC. They confirmed that no BPA is released under physiologic conditions from fissure sealants based on bis-GMA if pure base monomers are used. ADA suggests that the low level of BPA exposure that results from dental sealants and composites poses no health threat [43]. A "worst" sealant can release 930 micrograms of BPA. European regulations suggest that a child of 36 $\mathrm{kg}$ can tolerate a daily dose of over $1800 \mathrm{~g}$ BPA without any risks and a dose of $2500 \mathrm{~g}$ can be tolerated by an adolescent. Any acute dose of sealant is usually single or distributed, up to a maximum of four times. 44

\section{Prevention of Sealant Toxicity}

Rueggeberg et al. [44,45] used high-pressure liquid chromatography to analyze the amount of monomers-Bis-GMA; TEGDMA; and Bis-DMA-remaining after a) no treatment (the control treatment)b) 20-second rinse with an air-water syringe spray c) 20-second manual application of a dry cotton roll d) 20-second manual application of a wet cotton roll e)20-second manual application of a water/pumice slurry with a cotton pellet f) 20 -second application of a water/pumice slurry with a prophy cup on a slow-speed hand piece. They concluded that slurry of pumice is significantly more effective in removing the oxygen-inhibited layer from freshly cured sealants than either an air/water spray or wet or dry cotton alone. It has been confirmed that BPA and Bisphenol A dimethacrylate (BPA-DM) have proliferative effects in cells with high levels of estrogen receptors. However, BPA was not detected in American-made sealants, and BPA-DM was detectable in only a few.

In addition, researchers suggested that the surface layer of the sealant can be treated to reduce the possibility of unpolymerised BPA-DM being left on the tooth. They concluded that children are less likely to be exposed to BPA from sealants than from the ingestion of soft drinks or canned food. Sasaki et al. $[46,47]$ investigated the changes in the BPA concentration in saliva after restoration with 9 commercially available composite resins. Authors found that much less than $100 \mathrm{ng} / \mathrm{mL}$ of BPA were contained in the saliva after teeth were filled with composite resin, but that gargling with tepid water for 30 seconds can remove BPA from the oral cavity, making it an important risk management technique. Joskow et al. [48] measured BPA in saliva and urine samples collected at prescribed intervals after placements of appropriate amount of sealants in 14 individuals.

Saliva collection after sealant placement likely reduced systemic absorption of BPA from dental sealants. Authors recommended that sealants should be used in preventive dental practice. A new dimethacrylate monomer SiMA [49] without Bisphenol A (BPA) structure has been synthesized and used as base resin of dental composite materials with the aim of reducing human exposure to BPA derivatives. Extract of composite was used to evaluate its cytotoxic effect on humane dental pulp cells, and relative growth rate (RGR) was obtained by CCK-8 assay. Authors concluded that, SiMA had potential to replace Bis-GMA as base resin of dental composite materials. According to recommendations by Azarpazhooh and Main [50] the potential for BPA toxicity from the dental sealants can be reduced by using a mild abrasive, such as pumice, either on a cotton applicator or with a prophylaxis cup and having older children and adolescents gargle with tepid water for 30 seconds.

Washing the surface of the sealant for 30 seconds with an air-water syringe while using suction to remove fluids and debris from a child's mouth further reduces the chance of toxicity. Use of a rubber dam to control the operative field would further limit potential exposures [2]. To avoid adverse developmental effects, after prenatal exposure to BPA, elective use of resin containing dental sealants and composite restorations, during pregnancy should be minimized, and in cases of necessary application, isolation by rubber dam should be used.

\section{Conclusion}

Dental practitioners should treat the surface layer of sealant to avoid any possibility of unpolymerised BPA remaining on the tooth surface. Its exposure should be limited during pregnancy. The use of BPA and its derivatives free sealants and composites should be encouraged.

\section{References}

1. Nadal A, Ropero AB, Laribi O, Maillet M, Fuentes E, et al. (2000) Nongenomic actions of estrogens and xenoestrogens by binding at a plasma membrane receptor unrelated to estrogen receptor $\alpha$ and estrogen receptor $\beta$. Proc Natl Acad Sci USA 97(21): 11603-11608.

2. Fleisch FA, Sheffield PE, Chinn C, Edelstein BL, Landrigan PJ (2010) Bisphenol A and Related Compounds in Dental Materials. Pediatrics 126(4): 760-768.

3. Stone E, Ruoff L, Galland A, Passoff M (2010) Seeking safer packaging, ranking packaged food companies on BPA.

4. Staples CA, Dorn PB, Klecka GM, O’Block ST, Harris LR (1998) A review of the environmental fate, effects and exposures of bisfenol A Chemosphere 36(10): 2149-2173.

5. (2008) National Toxicology Program. NTP-CERHR monograph on the potential human reproductive and developmental effects of bisphenol A. NTP CERHR MON 22: i-III1.

6. Nathanson D, Lertpitayakun P, Lamkin MS, Edalatpour M, Chou LL (1997) In vitro elution of leachable components from dental sealants. J Am Dent Assoc 128(11): 1517-1523.

7. Soderholm KJ, Mariotti A (1999) BIS-GMA-based resins in dentistry: are they safe? J Am Dent Assoc 130(2): 201-209.

8. Tarumi H, Imazato S, Narimatsu M, Matsuo M, Ebisu S (2000) Estrogenicity of fissure sealants and adhesive resins determined by reporter gene assay. J Dent Res 79(11): 1838-1843.

9. Zafra A, del Olmo M, Pulgar R, Navalon A, Vilchez JL (2002) Determination of Bisphenol-A and related compounds in human saliva by gas chromatography- mass spectrometry. Chromatographia 56(3-4): 213-218. 
10. Arenholt Bindslev D, Breinholt V, Preiss A, Schmalz G (1999) Timerelated bisphenol-A content and estrogenic activity in saliva samples collected in relation to placement of fissure sealants. Clin Oral Investig 3(3): $120-125$.

11. Schmalz G, Preiss A, Arenholt Bindslev D (1999) Bisphenol-A content of resin monomers and related degradation products. Clin Oral Investig 3(3): 114-119.

12. Nathanson D, Ghulman M, Ashayeri N, Chou L (1999) In vitro estrogenic activity of leachable components from dental sealants and components (abstract 194) J Dent Res 78: 130.

13. Kuiper GG, Lemmen JG, Carlsson B, Corton JC, Safe SH, et al. (1998) Interaction of estrogenic chemicals and phytoestrogens with estrogen receptor beta. Endocrinology 139(10): 4252-4263.

14. Alonso Magdalena P, Laribi O, Ropero AB, Fuentes E, Ripoll C, et al. (2005) Low doses of bisphenol $\mathrm{A}$ and diethylstilbestrol impair Ca2signals in pancreatic alpha-cells through a nonclassical membrane estrogen receptor within intact islets of Langerhans. Environ Health Perspect 113(8): 969-977.

15. Ashby J, Tinwell H (1998) Uterotrophic activity of bisphenol A in the immature rat. Environ Health Perspect 106(11): 719-720.

16. Colerangle JB, Roy D (1997) Profound effects of the weak environmental estrogen-like chemical bisphenol A on the growth of the mammary bisphenol A on the growth of the mammary gland of Noble rats. J Steroid Biochem Mol Biol 60(1-2): 153-160.

17. Olea N, Pulgar R, Perez P, Olea Serrano F, Rivas A, et al. (1996) Estrogenicity of resin-based composites and sealants used in dentistry. Environ Health Perspect 104(3): 298-305.

18. Hashimoto Y, Moriguchi Y, Oshima H, Nishikawa J, Nishihara T, et al. (2000) Estrogenic activity of chemicals for dental and similar use in vitro. J Mater Sci Mater Med 11(8): 465-468.

19. Bonefeld Jørgensen EC, Long M, Hofmeister MV, Vinggaard AM (2007) Endocrine- disrupting potential of bisphenol A, bisphenol A dimethacrylate, 4-n-nonylphenol, and 4-noctylphenol in vitro: new data and a brief review. Environ Health Perspect 115(1): 69-76.

20. Mariotti A, Soderholm KJ, Johnson S (1998) The in vivo effects of bisGMA on murine uterine weight, nucleic acids and collagen. Eur J Oral Sci 106(6): 1022-1027.

21. Hanaoka T, Kawamura N, Hara K, Tsugane S (2002) Urinary bisphenol $\mathrm{A}$ and plasma hormone concentrations in male workers exposed to bisphenol A diglycidyl ether and mixed organic solvents. Occup Environ Med 59(9): 625-628.

22. Takeuchi T, Tsutsumi O, Ikezuki Y, Takai Y, Taketani Y (2004) Positive relationship between androgen and the endocrine disruptor, bisphenol A, in normal women and women with ovarian dysfunction. Endocr J 51(2): 165-169.

23. Sugiura Ogasawara M, Ozaki Y, Sonta S, Makino T, Suzumori K (2005) Exposure to bisphenol $\mathrm{A}$ is associated with recurrent miscarriage. Hum Reprod 20(8): 2325-2329.

24. http://www.fda.gov/NewsEvents/PublicHealthFocus/ucm064437.htm

25. Delclos BK, Camacho L, Lewis SM, Vanlandingham MM, Latendresse JR, et al. (2014) Toxicity Evaluation of Bisphenol A Administered by Gavage to Sprague Dawley Rats From Gestation Day 6 Through Postnatal Day 90. Toxicol Sci 153(1): 212.

26. Olea N, Pulgar R, Pérez P, Olea Serrano F, RivasA, et al. (1996) Estrogenicity of resin- based composites and sealants used in dentistry. Environ Health Perspect 104(3): 298-305.

27. Quinlan CA, Zisterer DM, Tipton KF, O'Sullivan MI (2002) In vitro cytotoxicity of a composite resin and compomer. Int Endod J 35(1): 4755.
28. Schweikl H, Hiller KA, Bolay C, Kreissl M, Kreismann W, et al. (2005) Cytotoxic and mutagenic effects of dental composite materials. Biomaterials 26(14): 1713-1719.

29. Pulgar R, Olea Serrano MF, Novillo Fertrell A, Rivas A, Pazos P, et al. (2000) Determination of bisphenol A and related aromatic compounds released from bis-GMA-based composites and sealants by high performance liquid chromatography. Environ Health Perspect 108(1): 21-27.

30. Nocca G, Chimenti C, Parziale V, Gambarini G, Giardina B, et al. (2006) In vitro comparison of the cytotoxicity of two orthodontic composite resins. Minerva Stomatol 55(5): 297-305.

31. Tell RT, Sydiskis RJ, Isaacs RD, Davidson WM (1988) Long-term cytotoxicityn of orthodontic direct-bonding adhesives. Am J Orthod Dentofacial Orthop 93(5): 419-422.

32. Al Hiyasat AS, Darmani H, Milhem MM (2005) Cytotoxicity evaluation of dental resin composites and their flowable derivatives. Clin Oral Investig 9(1): 21-25.

33. Wada $H$, Tarumi H, Imazato S, Narimatsu M, Ebisu S (2004) In vitro Estrogenicity of Resin Composites. J Dent Res 83(3): 222-226.

34. Fung EY, Ewoldsen NO, St Germain HA Jr, Marx DB, Miaw CL, et al. (2000) Pharmacokinetics of bisphenol A released from a dental sealant. J Am Dent Assoc 131(1): 51-58.

35. Ortengren U (2000) On composite resin materials. Degradation, erosion and possible adverse effects in dentists. Swed Dent J Suppl 141: 1-61.

36. Nomura Y, Ishibashi H, Miyahara M, Shinohara R, Shiraishi F, et al. (2003) Effects of dental resin metabolites on estrogenic activity in vitro. J Mater Sci Mater Med 14(4): 307-310.

37. Zimmerman Downs JM, Shuman D, Stull SC, Ratzlaff RE (2010) Bisphenol A Blood and Saliva Levels Prior To and After Dental Sealant Placement In Adults. J Dent Hyg 84(3): 145-150.

38. Kostoryz EL, Eick JD, Glaros AG, Judy BM, Welshons WV, et al. (2003) Biocompatibility of Hydroxylated Metabolites of BISGMA and BFDGE. J Dent Res 82(5): 367-371.

39. Manabe A, Kaneko S, Numazawa S, Itoh K, Inoue M, et al. (2000) Detection of bisphenol-A in dental materials by gas chromatographymass spectrometry. Dent Mater J 19(1): 75-86.

40. Hamid A, Hume WR (1997) A study of component release from resin pit and fissure sealants in vitro. Dent Mater 13(2): 98-102.

41. Lewis JB, Rueggeberg FA, Lapp CA, Ergle JW (1999) Identification and characterizationof estrogen-like components in commercial resin-based dental restorative materials. Clin Oral Investig 3(3): 107-113.

42. Schmalz G, Preiss A, Arenholt Bindslev D (1999) Bisphenol-A content of resin monomers and related degradation products. Clin Oral Investig 3(3): 114-119.

43. www.ada.org/member-center/oral-health-topics/bisphenol-a.

44. Eramo S, Urbani G, Sfasciotti GL, Brugnoletti O, Bossù M, et al. (2010) Estrogenicity of bisphenol A released from sealants and composites: a review of the literature. Ann Stomatol (Roma) 1(3-4): 14-21.

45. Rueggeberg FA, Dlugokinski M, Ergle JW (1999) Minimizing patients' exposure to uncured components in a dental sealant. J Am Dent Assoc 130(12): 1751-1757.

46. Schafer TE, Lapp CA, Hanes CM, Lewis JB (2000) What parents should know about estrogen-like compounds in dental materials. Pediatr Dent 22(1): 75-76.

47. Sasaki N, Okuda K, Kato T, Kakishima H, Okuma H, et al. (2005) Salivary bisphenol-A levels detected by ELISA after restoration with composite resin. J Mater Sci Mater Med 16(4): 297-300.

48. Joskow R, Barr DB, Barr JR, Calafat AM, Needham LL, et al. (2006) 
Exposure to bisphenol A from bis-glycidyl dimethacrylate-based dental sealants. J Am Dent Assoc 137(3): 353-362.

49. Liang X, Liu F, He J (2014) Synthesis of none Bisphenol A structure dimethacrylate monomer and characterization for dental composite applications. Dent Mater 30(8): 917-925.

\section{(C) (i) This work is licensed under Creative}

Submission Link: https://biomedres.us/submit-manuscript.php
50. Azarpazhooh A, Main PA (2008) Is There a Risk of Harm or Toxicity in the Placement of Pit and Fissure Sealant Materials? A Systematic Review. J Can Dent Assoc 74(2): 179-183.

Assets of Publishing with us
BIOMEDICAL
RESEARCHES

